\title{
Molecular Spectroscopic Study of Water Hyacinth Dry Matter
}

\author{
Medhat Ibrahim ${ }^{*}, \mathrm{a}, \mathrm{b}$, Oliver Kühn ${ }^{\mathrm{c}, \#}$ and Traugott Scheytt ${ }^{\mathrm{d}}$ \\ ${ }^{a}$ Spectroscopy Department, National Research Centre, Dokki, Cairo, Egypt \\ ${ }^{b}$ Physics Department, Faculty of Science, Jazan University, Jazan, Kingdom of Saudi Arabia, KSA \\ ${ }^{c}$ Institut für Chemie und Biochemie, Freie Universität Berlin, Takustr. 3, D-14195 Berlin, Germany \\ ${ }^{d}$ Technische Universität Berlin, Institut für Angewandte Geowissenschaften, Fachgebiet Hydrogeologie, D-13355, \\ Berlin, Germany \\ \#New address: Institut für Physik, Universität Rostock, Universitätsplatz 3, D-18051 Rostock, Germany
}

\begin{abstract}
The potential use of water hyacinth dry matter for removing heavy metals from wastewater is studied by combining various spectroscopic techniques and quantum chemical ab initio calculations. The aquatic plant water hyacinth was treated with $0.025,0.050,0.100,0.200$, and $0.400 \mathrm{M}$ acetic acid for different times up to 19.0 hours. The plant was divided into root and shoot then dried and grinded into pieces of $200 \mu \mathrm{m}$ in diameter. FTIR measurements revealed that acetate finds its way to the plant root and is then transported to the shoot. Furthermore, it is shown that the treated and dried plant can be used to mediate $\mathrm{Cd}$ from wastewater. FAAS results indicate that $55 \%$ of $\mathrm{Cd}$ (in case of low concentration) and $80 \%$ of $\mathrm{Cd}$ (in case of higher concentration) could be removed from wastewater within 2.0 hours. The coordination of acetate to the plant was assumed to happen via the cellulose of the plant where also the Cd uptake takes place. This is confirmed by studying changes in the absorption of the $\mathrm{C}=\mathrm{O}$ stretching band of cellulose acetate subject to $\mathrm{CdCl}_{2}$ by FTIR and by a cellulose monomer quantum chemical model.
\end{abstract}

Keywords: FAAS, FTIR, water hyacinth, phytoremediation, density functional theory.

\section{INTRODUCTION}

The phenomena of pollutants uptake by aquatic plants were studied by Sheffield and Orens decades ago [1,2]. Later on water hyacinth among other aquatic plants showed a potential to remove pollutants when being used as a biological filtration system $[3,4]$. It could remove several heavy metals and other pollutants as reported in Refs [5-12]. This triggered efforts directed towards the utilization of water hyacinth as an effective phytoremediation tool [13-16]. As a caveat we note, that it has been reported that water hyacinth could be a serious environmental problem on its own. It reduces sunlight penetration and lowers the oxygen content of water, which has a great impact on the water ecosystem [1720].

Fourier Transform Infrared (FTIR) among other spectroscopic methods was employed extensively in cellulose research, e.g., it gives access to the structural modifications of cellulose [21]. Molecular modeling can provide valuable information concerning the optimization of applications of cellulose through explaining its molecular as well as other properties. For instance, the interaction of cellulose with dye fibers was studied by AM1 semiempirical molecular orbital calculations [22]. Polycyclic dyes were used by Wojciechowski and Wolska for dyeing cellulose fibers and with

*Address correspondence to this author at the Spectroscopy Department, National Research Centre, Dokki, Cairo, Egypt;

E-mail: medahmed6@yahoo.com
AM1 computations sulpho group substitution sites were predicted [23]. Higher levels of theory like Density Functional Theory (DFT) was used by Terzyk in order to characterize the microporosity of carbon films which are obtained from cellulose [24]. DFT was also applied to study the effect of hydroxyl propyl cellulose on pore structure of carbons coated on ceramic particles [25]. Two carbenium-iminium ions are derived from the widely used oxidant and cellulose $\mathrm{N}$-methylmorpholine-N-oxide by heterolytic degradation. The corresponding reaction mechanism was investigated in Ref [26]. Finally, we mention that cellulose esters are part of cellulose derivatives that have long history in industrial as well as pharmaceutical applications [27-29].

In our previous work atomic emission spectroscopy was used to study the concentrations of $\mathrm{Cu}, \mathrm{Pb}$, and $\mathrm{Ni}$ in water hyacinth root [30]. Further, both the dielectric constant and dielectric loss were estimated for plant roots collected from the Nile river [31]. In addition, studying the interaction between organic and inorganic structures through the acetate group has been subject of our molecular modeling work [32, 33]. Moreover, we have demonstrated that dry water hyacinth plant could remove $\mathrm{Cd}$ from polluted water [34]. The process is described in terms of the interaction between acetate and hexahydrated $\mathrm{Cd}$. However, no explanation for the fate of acetate in the plant could be given so far.

In the present paper we will further elaborate on the benefits of water hyacinth dry matter. The plant has been subjected to acetic acid at different molarities and times. The molecular structure as well as the degree of acetylation was studied using 
FTIR spectroscopy. Since for the process under investigation the plant can be considered as cellulose like material, we have chosen to study cellulose acetate as a minimum model which is also amenable to $a b$ initio quantum chemical calculations. This also allows investigating the binding sites of $\mathrm{Cd}$ in the acetylated cellulose. From the comparison with treated plants immersed in a wastewater containing $\mathrm{Cd}$ we can draw conclusions on the $\mathrm{Cd}$ uptake which is measured using Flame Atomic Absorption Spectroscopy (FAAS).

\section{MATERIALS AND METHODOLOGY}

\section{Reagents}

Cadmium chloride dried LR (MW 183.32) was purchased from S.d. Fine-Chem Ltd., Cellulose acetate with $39.7 \mathrm{wt} \%$ acetyl content was purchased from Aldrich chemical company, Inc., USA. Both potassium bromide and acetic acid anhydride (which was used without further purification) were obtained from Aldrich-Chemicals. Cadmium standard solution was purchased from Merck, Germany.

\section{Sample Collection and Preparation}

Water hyacinth plant was collected $(10 \mathrm{~cm}$ length) from the river Nile at Rod El-Farag, north of Cairo. It was divided into groups; each group was immersed in $0.025,0.050,0.100$, 0.200 , and $0.400 \mathrm{M}$ acetic acid, respectively, for 19.0 hours. Other groups were subjected to $0.100 \mathrm{M}$ acetic acid for 0.5 , $1.0,2.0,4.0,12.0$, and 19.0 hours.

Water hyacinth was washed thoroughly with doubly distilled water and was then divided into shoot and root; dried separately at $65^{\circ} \mathrm{C}$ till constant weight. $\mathrm{CdCl}_{2}$ was mixed with cellulose acetate as $1: 1$ and 1:2 in powder form and grinded into pieces of $200 \mu \mathrm{m}$ in diameter carefully. Acetylated water hyacinth root and shoot were separately treated with $0.10 \%$ $\mathrm{CdCl}_{2}$ solution for 24.0 hours then studied by FTIR. A synthetic wastewater containing 0.2 and $1.2 \mathrm{mg} / \mathrm{l} \mathrm{Cd}$ was prepared. Then $2.5 \mathrm{~g}$ of root shoot and mixtures of root and shoot separately were immersed in 1.0 liter of the synthetic wastewater samples. Water samples were collected at $0.0,1.0,2.0$, 3.0, 6.0, and 9.0 hours respectively. Both the standard and the synthetic solutions of $\mathrm{Cd}$ were prepared by dilution from $1000.0 \mathrm{mg} / 1$ stock solution.

\section{Instrumentation}

The FTIR spectra were collected for the studied samples using the spectrometer JASCO, FTIR-300 E at the Spectroscopy Department, National Research Centre, Egypt, which covers the range from 400 to $4000 \mathrm{~cm}^{-1}$. The $\mathrm{KBr}$ disc technique was followed for the FTIR study, that is, each sample (plant root, plant shoot, cellulose acetate $/ \mathrm{CdCl}_{2}$ mixture and root/shoot mixture) was mixed with $\mathrm{KBr}(1.0 \% \mathrm{w} / \mathrm{w})$ and pressed in pellets.

The NovAA 400 Jena Flame Atomic Absorption Spectrometer, at the Hydrogeology Department, TU Berlin, Germany, was used for the determination of $\mathrm{Cd}$ concentration. The operational conditions were as follows: $3.0 \mathrm{~mA}$ lamp current, $228.8 \mathrm{~nm}$ spectral line, $8.0 \mathrm{~mm}$ burner height, $5.0 \mathrm{~s}$ measuring time using air acetylene flame [34].

\section{Calculation Details}

A cellulose monomer (4-1 linkage) was chosen as a model molecule as shown in Fig. (5) below. Since sites 1 and 4 are blocked, we only considered substitutions at sites 2,3 , and 6. In principle cellulose acetate contains the acetyl group, $-(\mathrm{C}=\mathrm{O}) \mathrm{CH}_{3}$. Below we will argue that such a model is not in accord with the experiments. However, a structure which does conform with the observations should contain carboxyl groups, $-(\mathrm{C}=\mathrm{O}) \mathrm{OH}$, replacing the hydroxyl groups at sites 2,3 , and 6 . Therefore, in order to get some general idea about the correlation of structural and spectral changes we have chosen to study in fact cellulose carboxylates. Geometry optimization and harmonic frequency analysis has been performed using DFT with the B3LYP functional and the effective core LANL2DZ basis set as implemented in the Gaussian 03 program package [35].

\section{RESULTS AND DISCUSSION}

\section{FTIR Study of Plant Acetylation}

Figs. $(\mathbf{1}, \mathbf{2})$ present the FTIR spectra of water hyacinth after acetic acid treatment with molarities up to $0.400 \mathrm{M}$ and times up to 19.0 hours. In general the spectra of shoot and root could be assigned as follows [36, 37]: The $\mathrm{OH}$ bands of water are found at $3388.3 \mathrm{~cm}^{-1}$ and $1422.2 \mathrm{~cm}^{-1}$. The $\mathrm{CH}_{2}$ group contributes two bands at 2922.6 and $1371.1 \mathrm{~cm}^{-1}$ while the $\mathrm{CH}_{3}$ stretching vibration is located at $2852.2 \mathrm{~cm}^{-1}$. The $\mathrm{C}=\mathrm{O}$ stretching band which is the characteristic band of the carbonyl group appears around $1736.5 \mathrm{~cm}^{-1}$; this band is found already in plant shoot but it becomes more intense as a result of treating the plant with acetic acid. Previously, we observed [36] that the interaction of hydrated divalent metals with organic acids leads to the appearance of the caboxylate band around $1620 \sim 1650 \mathrm{~cm}^{-1}$. In the present work this band occurs around $1634.4 \mathrm{~cm}^{-1}$ and is assigned as a $\mathrm{COH}$ vibration. This assumption is confirmed by the observation of the asymmetric stretching vibration of $\mathrm{COO}$ at $1516.7 \mathrm{~cm}^{-1}$. The latter band is regarded as a weak band, so that one can conclude that the $\mathrm{COH}$ band at $1634.4 \mathrm{~cm}^{-1}$ is coupled to the bending vibration of water and not only attributed to metal uptake. However, in general the $1634.4 \mathrm{~cm}^{-1}$ band is an important marker for the uptake of hydrated metals by water hyacinth in Nile water. The C-O stretching vibration of the cellulose backbone is at $1035.6 \mathrm{~cm}^{-1}$.

The FTIR technique is highly sensitive and reliable for the determination of the degree of carboxylation. The latter is obtained from the ratio between the intensity of the $\mathrm{C}=\mathrm{O}$ stretching band at $1736.5 \mathrm{~cm}^{-1}$ and the intensity of the backbone $\mathrm{C}-\mathrm{O}$ stretching vibration at $1035.6 \mathrm{~cm}^{-1}$ [38]. Table 1 presents the degree of carboxylation for shoot and root after treating the plant with $0.025,0.050,0.100,0.200$, and 0.400 $\mathrm{M}$ acetic acid. Results show that this process takes place for all the studied acid molarities with no significant variation even in terms of time which could be due to the limited time resolution. We further find a decrease in the degree of carboxylation in the root followed by a corresponding increase in the shoot. The latter effect could be attributed to a possible transport from root to shoot which may be enhanced at 0.050 

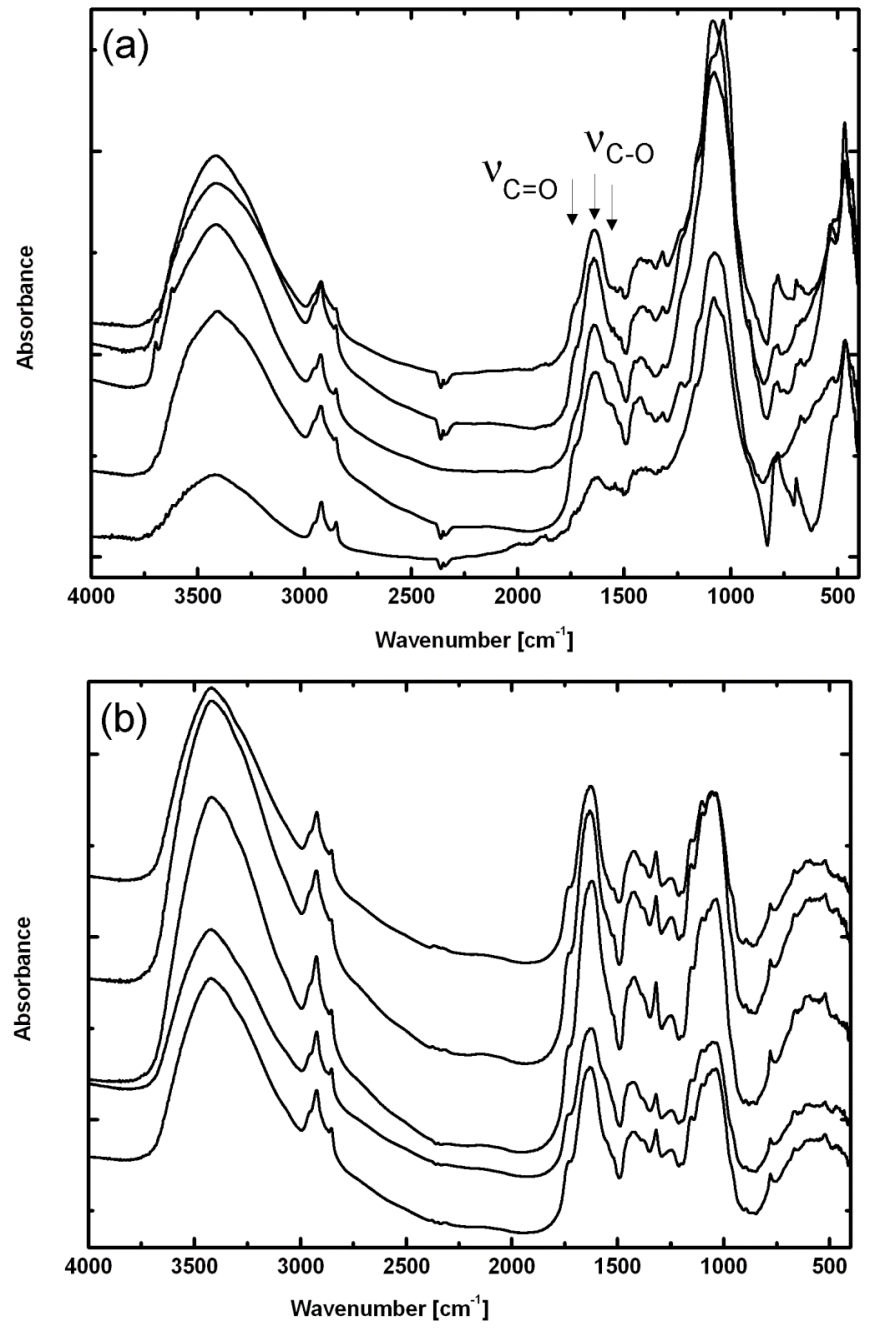

Fig. (1). FTIR spectra of water hyacinth root (a) and shoot (b) samples treated with different acetic acid concentrations $(0.025,0.50$, 1.0, 2.0 and 4.0 M from bottom to top) at constant time (19 hours).

M. Additional support comes from the fact that the spectra show no absorption bands in the region of $1840-1760 \mathrm{~cm}^{-1}$ which indicates that these samples are free of unreacted acetic anhydride. Furthermore, no bands were found at $1700 \mathrm{~cm}^{-1}$ which gives evidence that the treated samples are free of acetic acid by-products. Overall we should also point out that our observations are in good agreement with previous results reported in Refs [38, 39]. Therefore, one can conclude that treating water hyacinth with acetic acid gives rise to $\mathrm{C}=\mathrm{O}$ aborption even at high acid molarities. This supports the assumption that treating the plant leads to carboxylation of its cellulose content. Furthermore, the underlying process sustained irrespective possible deacylation processes.

\section{Removal of Cadmium from Water}

Treated water hyacinth root, shoot, and a mixture of root and shoot were immersed in a wastewater containing 0.2 and $1.2 \mathrm{mg} / \mathrm{l} \mathrm{Cd}$, respectively. Wastewater which is subjected to treated plants was collected and analysed with flame atomic absorption; the results are summarized in Table 2. They clearly indicate that treated water hyacinth root and samples. While at lower $\mathrm{Cd}$ concentration the removal by the shoot could remove $\mathrm{Cd}$ from wastewater better than untreated
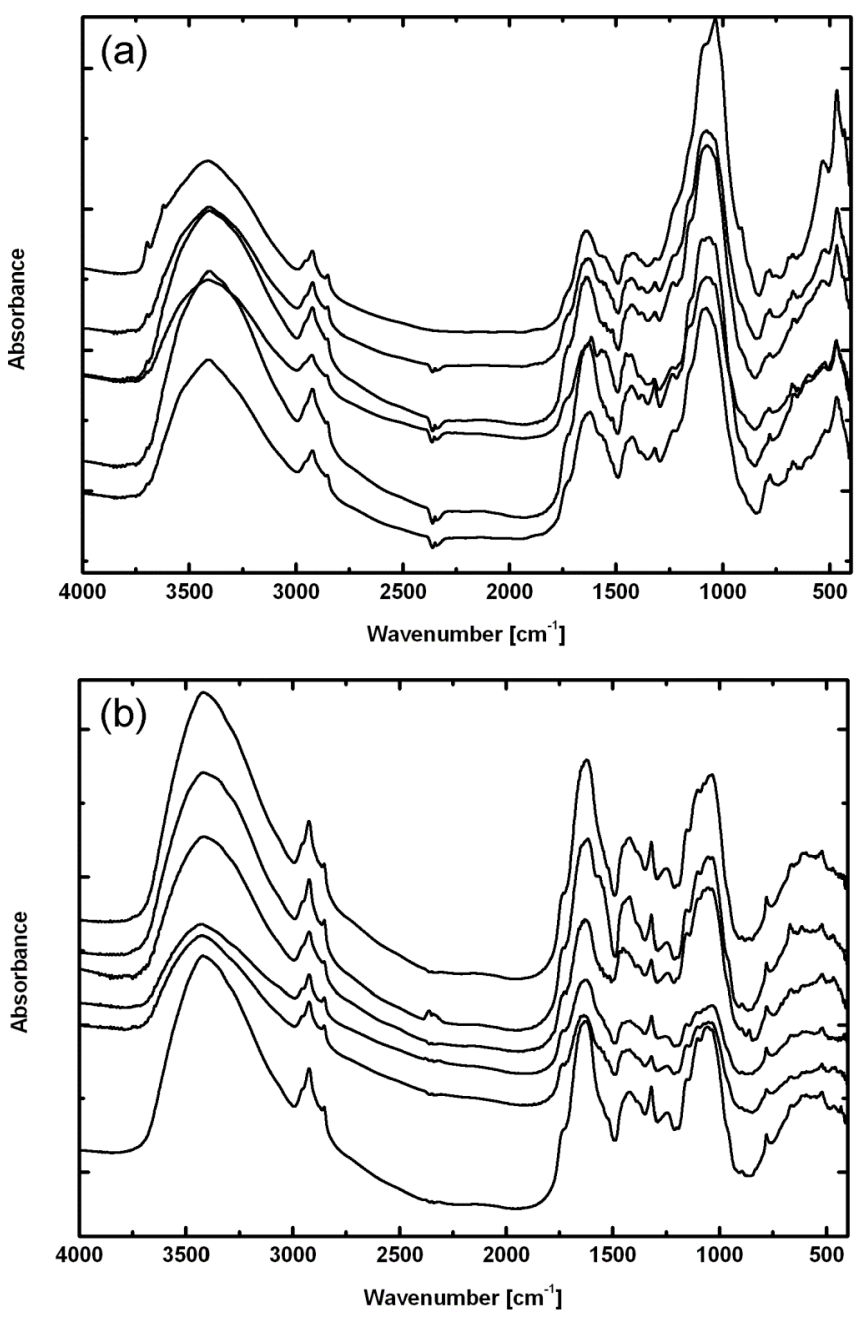

Fig. (2). FTIR spectra of water hyacinth root (a) and shoot (b) samples treated with $0.100 \mathrm{~N}$ acetic acid at different times (30 min, 1, 2, $4,12,19 \mathrm{~h}$, from bottom to top).

shoot is more effective, the roots perform better at higher concentration. The reason for this behaviour is not clear at the moment. We have also studied mixed root/shoot samples (1:1) which enhances the removal of $\mathrm{Cd}$ in the low concentration case, but falls below the performance of untreated root and shoot in the high concentration regime. Generally treated plants show higher ability to remove $\mathrm{Cd}$ from the studied solution as compared with untreated samples. Furthermore, we notice that the ability of plants to remove $\mathrm{Cd}$ is not only increased by treatment, but also the uptake rate increases. For instance, within 2 hours treated plants could remove about $55 \%$ of $\mathrm{Cd}$ in case of low concentration and $80 \%$ of $\mathrm{Cd}$ in case of higher concentration. On the other hand, the untreated plant needs 96 hours to mediate $40 \%$ of $\mathrm{Cd}$ in case of lower concentration and to mediate $85 \%$ of $\mathrm{Cd}$ in case of higher concentration.

\section{FTIR and Quantum Chemical Study of a Cellulose Model}

\section{Experiment}

In order to develop some microscopic understanding of these findings we have studied a model system, that is, 
Table 1. Calculated Degree of Carboxylation $\left(A_{1740} / A_{1035.6}\right)$ for Water Hyacinth which Treated with Acetic Acid at Different Molarities (19h) and Times (0.1M)

\begin{tabular}{|c|c|c|}
\hline Acetic Acid & Shoot & Root \\
\hline \multicolumn{3}{|c|}{ at Different Acetic Acid Molarities } \\
\hline 0.025 & 0.6787 & 0.5753 \\
\hline 0.050 & 0.7390 & 0.5134 \\
\hline 0.100 & 0.6262 & 0.3969 \\
\hline 0.200 & 0.6215 & 0.4652 \\
\hline 0.400 & 0.9630 & 0.4782 \\
\hline \multicolumn{3}{|l|}{ at Different Times } \\
\hline 0.500 & 0.6577 & 0.5119 \\
\hline 1.000 & 0.7022 & 0.4844 \\
\hline 2.000 & 0.8126 & 0.5490 \\
\hline 4.000 & 0.8625 & 0.4630 \\
\hline 12.000 & 0.6439 & 0.4545 \\
\hline 19.000 & 0.6262 & 0.3969 \\
\hline
\end{tabular}

Table 2. Concentration of $\mathrm{Cd}$ (in $\mathrm{mg} / \mathrm{l}$ ) as a Function of Time

\begin{tabular}{|c|c|c|c|c|c|}
\hline \multirow{2}{*}{ Time, Hours } & \multicolumn{2}{|c|}{ Root (R) } & \multicolumn{2}{c|}{ Shoot (S) } & R+S \\
\cline { 2 - 6 } & Untreated & Treated & Untreated & Treated & Treated \\
\hline \hline Starting with 0.2 mg/l Cadmium \\
\hline 0.0 & 0.1993 & 0.1993 & 0.1993 & 0.1993 & 0.1993 \\
\hline 1.0 & 0.2215 & 0.1033 & 01445 & 0.0932 & 0.1046 \\
\hline 2.0 & 0.1584 & 0.0953 & 0.1291 & 0.0918 & 0.1050 \\
\hline 3.0 & 0.1432 & 0.1040 & 0.1696 & 0.0978 & 0.1068 \\
\hline 6.0 & 0.1281 & 0.0947 & 0.1593 & 0.0978 & 0.1073 \\
\hline 9.0 & 0.1270 & 0.0989 & 0.1590 & 0.0887 & 0.1017 \\
\hline 96.0 & 0.1020 & & 0.1181 & & \\
\hline Starting with 1.2 mg/l Cadmium & & & \\
\hline 0.0 & 1.1700 & 1.1700 & 1.1700 & 1.1700 & 1.1700 \\
\hline 1.0 & 0.6288 & 0.2874 & 0.6502 & 0.3674 & 0.2980 \\
\hline 2.0 & 0.5266 & 0.2169 & 0.3816 & 0.3272 & 0.2986 \\
\hline 3.0 & 0.3040 & 0.2156 & 0.4118 & 0.2987 & 0.2751 \\
\hline 6.0 & 0.3263 & 0.2609 & 0.2838 & 0.3007 & 0.2971 \\
\hline 9.0 & 0.2755 & 0.2834 & 0.2375 & 0.3138 & 0.3078 \\
\hline 96.0 & 0.1376 & & 0.2434 & & \\
\hline
\end{tabular}

cellulose acetate (CA) which is also amenable to quantum chemical calculations. FTIR spectra of the untreated and treated plants are compared with that of CA in Fig. (3). The different spectra indicate that there should be similarities in the molecular structures. In particular there is a strong band at $1750 \mathrm{~cm}^{-1}$ which corresponds to a $\mathrm{C}=\mathrm{O}$ vibration, $v_{\mathrm{C}=0}$, and correlates to the band observed at $1736 \mathrm{~cm}^{-1}$ in the plant. Hence, CA should be a suitable model system for studying the mechanistic details of the role of acetate in the Cd uptake of treated plants. In passing we note that one can in fact identify two bands upon taking the second derivative of the $\mathrm{C}=\mathrm{O}$ band in the cellulose acetate spectrum. However, upon polymerization these two bands merge into a single broad band. The same broadening is observed for other bands such as those related to the $\mathrm{OH}$ or $\mathrm{CH}_{2} \mathrm{OH}$ vibrations. Finally, we notice that treated root and shoot samples have been subject to $0.10 \% \mathrm{CdCl}_{2}$ solution which leads to the appearance of a

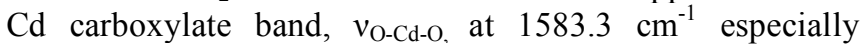
prominent for the root sample (see arrow in Fig. 3).

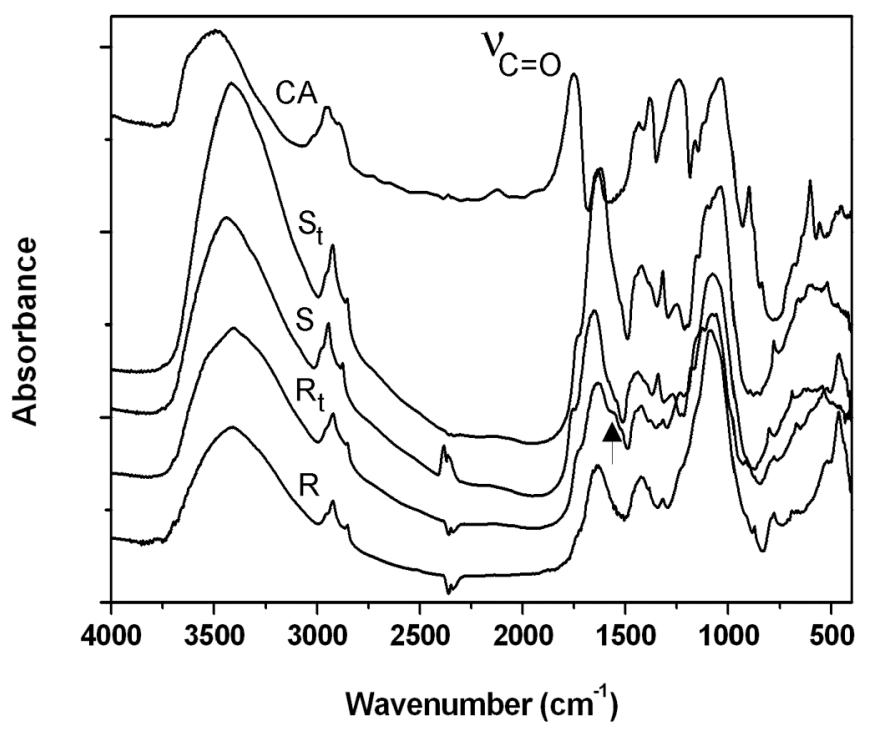

Fig. (3). FTIR spectra for cellulose acetate (CA), acid treated water hyacinth root $\left(\mathrm{R}_{\mathrm{t}}\right)$ and shoot $\left(\mathrm{S}_{\mathrm{t}}\right)$ as compared with non treated plant shoot $(\mathrm{S})$ and root $(\mathrm{R})$. Acetylated water hyacinth root and shoot were treated with $0.10 \% \mathrm{CdCl}_{2}$ solution for 24.0 hours. The arrow marks the position of the $\mathrm{Cd}$ carboxylate band.

Following these lines we have also studied mixtures of $\mathrm{CA}$ and $\mathrm{CdCl}_{2}$. The FTIR spectra obtained for different mixtures are reported in Fig. (4). The spectra of $\mathrm{CdCl}_{2} /$ Cellulose mixture indicate the appearance of a new band at $1583.3 \mathrm{~cm}^{-1}$ and the simultaneous disappearance of the $\mathrm{C}=\mathrm{O}$ band at 1750 $\mathrm{cm}^{-1}$. We argue that the band at $1583.3 \mathrm{~cm}^{-1}$ arises from the coordination of $\mathrm{Cd}$ to the deprotonated $\mathrm{COOH}$ group, i.e., it could be assigned to the Cd-carboxylate band, $v_{\mathrm{O}-\mathrm{Cd}-\mathrm{O}}$. Notice that this band would not be observed in the presence of an acetyl group.

The assumption is further supported by comparison with Fig. (3) which shows the $\mathrm{Cd}$ carboxylate band at the same frequency $1583.3 \mathrm{~cm}^{-1}$. This indicates that the plant behaves like cellulose when both of them interact with $\mathrm{CdCl}_{2}$ which in turn leads us to treat water hyacinth in this removal process as cellulose material. Furthermore, the treated plant is acting as cellulose carboxylate in this case. However, the small difference in the spectra of the treated plant and cellulose acetate indicate that most likely not all cellulose units are carboxylated. 


\section{Quantum Chemistry Results}

Optimized structures for different models of cellulose carboxylate and as well as $\mathrm{CdCl}_{2}$ coordinated species are shown in Fig. (5) and harmonic frequencies of relevant transitions are compared to the experimental data in Table 3. As a general trend we observe that the harmonic frequencies are too low by about $3 \%$. This is not surprising given the simple monomer model which in particular neglects interactions with neighboring cellulose units which could lead to some sort of confinement of nuclear motions. Second, we observe that there is not much difference between the $\mathrm{C}=\mathrm{O}$ vibrations at different sites; the biggest difference is in the dicarboxylate which also shows a small blue-shift attributed to a confinement effect. Since there is only one discernible $v_{\mathrm{C}=\mathrm{O}}$ feature in the experiment from these data it cannot be concluded how many sites are carboxylated as the transitions coincide taking into account the expected error bar. $\mathrm{CdCl}_{2}$ attaches to the carboxyl group as shown in Fig. (5e, f). Inspecting Table 3 we notice that this gives rise to the fundamental transition of $v_{\mathrm{O}-\mathrm{Cd}-\mathrm{O}}$ at $1523 \mathrm{~cm}^{-1}$ which, similar to the $v_{\mathrm{C}=\mathrm{O}}$ case above, underestimates the experimental value by about $4 \%$. Interestingly, also the $v_{\mathrm{C}=\mathrm{O}}$ transition is red shifted which is not in accord with the experiment. One possible interpretation would be that there is only one carboxyl group per monomer and the changes in the signal reflect the relative number of groups coordinated to $\mathrm{CdCl}_{2}$. However, an alternative possibility would have di-carboxylate with either the site 2 or 3 and site 6 carboxylated (see Fig. 5f). As seen from Table 3 this would not affect the position of the $\mathrm{V}_{\mathrm{C}=\mathrm{O}}$ fundamental transition.

Table 3. Harmonic Frequencies (in $\mathrm{cm}^{-1}$ ) of the Relevant Vibrations of Different Cellulose Models as Obtained Using DFT/B3LYP with a LANL2DZ Effective Core Potential (For Structures See Fig. 5).

\begin{tabular}{|c|c|c|c|}
\hline Structure & Calculation & Experiment & Assignment \\
\hline Cellulose carboxylate (2) & 1697 & 1750 & $v_{\mathrm{C}=\mathrm{O}}$ \\
\hline Cellulose carboxylate (3) & 1695 & 1750 & $v_{\mathrm{C}=\mathrm{O}}$ \\
\hline Cellulose di-carboxylate (2-3) & $\begin{array}{l}1710 \\
1723\end{array}$ & 1750 & $v_{\mathrm{C}=\mathrm{O}}$ \\
\hline $\begin{array}{l}\mathrm{CdCl}_{2} \text { cellulose di-carboxylate } \\
(2-3)\end{array}$ & $\begin{array}{l}1523 \\
1661\end{array}$ & $\begin{array}{l}1583 \\
1750\end{array}$ & $\begin{array}{c}v_{\mathrm{O}-\mathrm{Cd}-\mathrm{O}} \\
v_{\mathrm{C}=\mathrm{O}}\end{array}$ \\
\hline $\begin{array}{l}\mathrm{CdCl}_{2} \text { cellulose di-carboxylate } \\
(2-6)\end{array}$ & $\begin{array}{l}1519 \\
1716\end{array}$ & $\begin{array}{l}1583 \\
1750\end{array}$ & $\begin{array}{c}v_{\mathrm{O}-\mathrm{Cd}-\mathrm{O}} \\
v_{\mathrm{C}=\mathrm{O}}\end{array}$ \\
\hline
\end{tabular}

\section{CONCLUSIONS}

In summary we have shown that water hyacinth which is subjected to acetic acid is able to absorb acetate which finds it way to the cellulose of the plant. The dried and treated system acts like carboxylated cellulose and in particular it can accelerate the removal of $\mathrm{Cd}$ from the aquatic environment. Although the details of the ongoing reactions are not known, some mechanistic aspects can be gathered by studying a cellulose acetate model. Combining spectroscopic and quantum chemical investigations we suggest a model where
$\mathrm{Cd}$ is coordinated to the deprotonated carboxyl group which replaces the hydroxyl group of the cellulose.

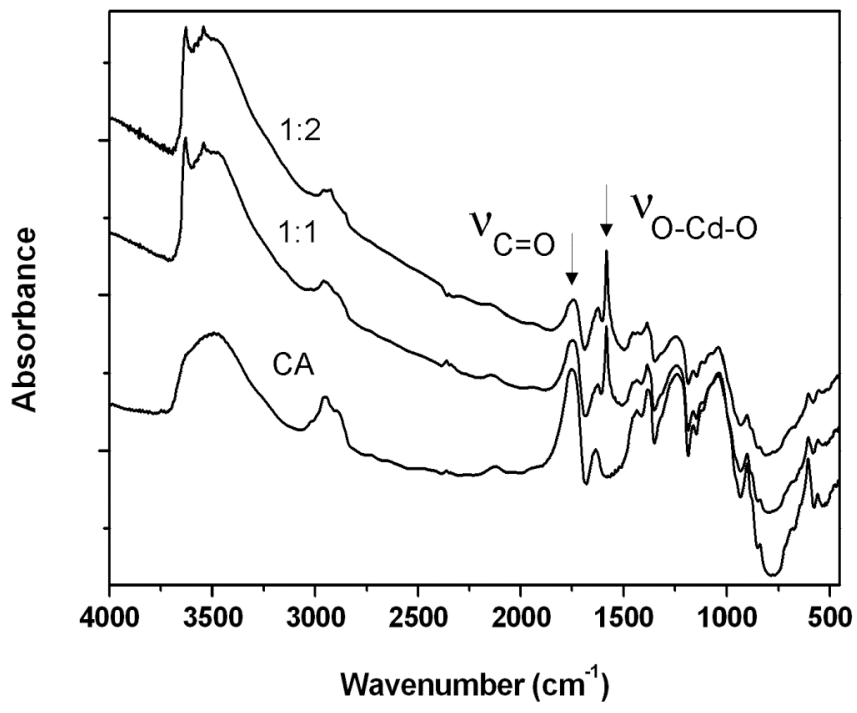

Fig. (4). FTIR spectra for cellulose acetate, cellulose acetate mixed with $\mathrm{CdCl}_{2}$ as 1:1 and cellulose acetate mixed with $\mathrm{CdCl}_{2}$ as 1:2. (a)

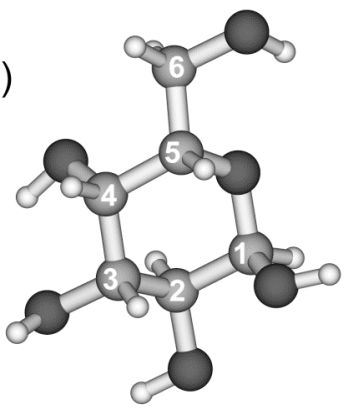

(c)

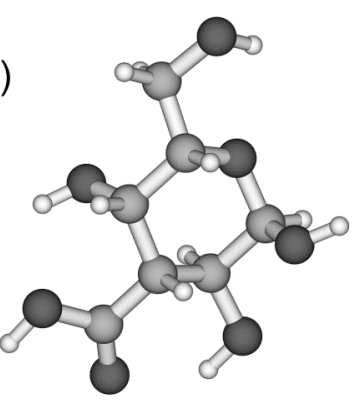

(e)

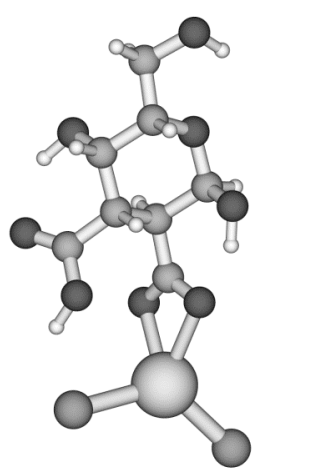

(b)

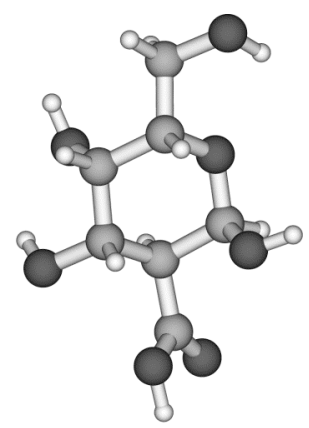

(d)

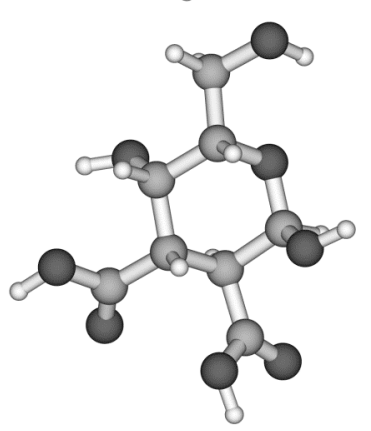

(f)

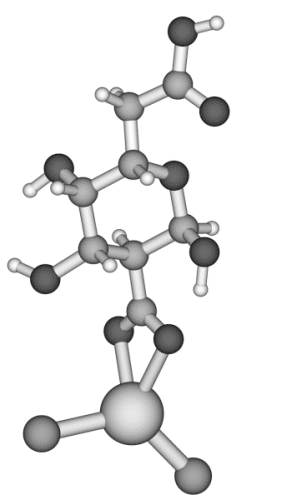

Fig. (5). Cellulose monomer model assuming a 1-4 linkage as well as various carboxylated and $\mathrm{CdCl}_{2}$ coordinated species. The structures have been obtained at the DFT/B3LYP/LANL2DZ level of theory. 
The demonstration of the merits of treated and dried water hyacinth for remediation purposes has the additional advantage that it reduces or even eliminates the diverse impact of the water hyacinth on the aquatic environment. Our present finding together with our results from previous studies [40] strongly supports our suggestion that the cellulose of the plant plays an important role in the process of phytoremediation

\section{REFERENCES}

[1] Sheffield CW. Water hyacinth for nutrient removal. Hyacinth Control J 1967; 6: 27-30.

[2] Ornes WH, Sutton DL. Removal of phosphorus from static sewage by water hyacinth. Hyacinth Control J 1975; 13: 56-8.

[3] Wolverton C, Macdonald RC. Water hyacinths and alligator weeds for final filtration of sewage. Technical Memorandum TM-X72729, NASA: Washington, D.C.; October 1975.

[4] Murmato S, Oki Y. Removal of some heavy metals from polluted water by water hyacinth. Bull Environ Contam Toxicol 1983; 30: 170-7.

[5] Rosas I, Carbajal ME, Gómez-Arroyo S, Belmont R, VillalobosPietrini R. Cytogenetic effects of cadmium accumulation on water hyacinth (Eichhornia crassipes). Environ Res 1984; 33: 386-95.

[6] So LM, Chu LM, Wong PK. Microbial enhancement of $\mathrm{Cu}^{2+}$ removal capacity of Eichhornia crassipes (Mart.). Chemosphere 2003; 52: 1499-503.

[7] Hasan SH, Talat M, Rai S. Sorption of cadmium and zinc from aqueous solutions by water hyacinth (Eichchornia crassipes). Biores Techn 2007; 98: 918-28.

[8] Shamik D, Jana BB. Distribution pattern of ambient cadmium in wetland ponds distributed along an industrial complex. Chemosphere 2004; 55: 175-85.

[9] Skinner K, Wright N, Porter-Goff E. Mercury uptake and accumulation by four species of aquatic plants. Environ Pollut 2007; 145: 234-7.

[10] Huilong X, Xiangjuan M. Phytoremediation of ethion by water hyacinth (Eichhornia crassipes) from water. Biores Techn 2006; 97: $1050-4$.

[11] Youngchul K, Giokas DL, Jin-Woo L, Paraskevas PA. Potential of natural treatment systems for the reclamation of domestic sewage in irrigated agriculture. Desalination 2006; 189: 229-42.

[12] Mathias E, Evangelou MWH, Schaeffer A. Cyanide phytoremediation by water hyacinths (Eichhornia crassipes). Chemosphere 2007; 66: 816-23.

[13] Ntengwe FW. An overview of industrial wastewater treatment and analysis as means of preventing pollution of surface and underground water bodies-the case of nkana mine in Zambia. Phys Chem Earth Parts A-C 2005; 30: 726-34.

[14] Maine MA, Suñe N, Hadad H, Sánchez G, Bonetto C. Nutrient and metal removal in a constructed wetland for wastewater treatment from a metallurgic industry. Ecologic Eng 2006; 26: 341-7.

[15] Mishima D, Tateda M, Ike M, Fujita M. Comparative study on chemical pretreatments to accelerate enzymatic hydrolysis of aquatic macrophyte biomass used in water purification processes. Biores Techn 2006; 97: 2166-72.

[16] Verma VK, Singh YP, Rai JPN. Biogas production from plant biomass used for phytoremediation of industrial wastes. Biores Techn 2007; 98: 1664-9.

[17] Fayad YH. Water hyacinth infestations and control in Egypt: Proceedings of the $1^{\text {st }}$ IOBC Water Hyacinth Working Group 1998; 106-10.

[18] Masifwa WF, Twongo T, Denny P. The impact of water hyacinth, Eichhornia crassipes (Mart.) Solms on the abundance and diversity of aquatic macroinvertebrates along the shores of northern Lake Victoria, Uganda. Hydrobiol 2001; 452: 79-88.

[19] Jian-Jun C, Yi D, Qi-Jia Z. Invasion and control of water hyacinth (Eichhornia crassipes) in China. J Zhejiang Univ Sci B 2006; 7(8): 623-6.

[20] Toft JD, Simenstad CA, Cordell JR, Gremaldo LF. The effects of introduced water hyacinth on habitat structure, invertebrate assemblages, and fish diets. Estuaries 2003; 26: 746-58.

[21] Manito-Pereira AM, Lopes MC, Timmer JMK, Keurentjes JTF. Solvent sorption measurements in polymeric membranes with ATR-IR spectroscopy. J Memb Sci 2005; 260: 174-80.

[22] Martínez-Urreaga J, de la Orden MU. Modification of cellulose with amino compounds: A fluorescence study. Carbohydr Polym 2007; 69: 14-9.

[23] Wojciechowski K, Wolska A. Substantivity and spatial structure of soluble polycyclic dyes for dyeing cellulose fibres. Dyes Pigments 2005; 65: 111-6.

[24] Terzyk AP, Gauden PA, Zawadzki J, Rychlicki G, Wisniewski M, Kowalczyk P. Toward the characterization of microporosity of carbonaceous films. J Coll Interf Sci 2001; 243: 183-92.

[25] Corrales F, Vilaseca F, Llop M, Gironès J, Méndez JA, Mutjè P. Chemical modification of jute fibers for the production of greencomposites. J Hazard Mat 2007; 144: 730-5.

[26] Fabian W, Timofei S, Kurunczi L. Molecular field analysis, semiempirical (AM1) molecular orbital and multiconformational minimal steric difference (MTD) calculations of anthraquinone dye-fibre affinities. J Mol Struct (Theochem) 1995; 340: 73-81.

[27] Zhang H, Kannangara D, Hilder M, Ettl R, Shen W. The role of vapour deposition in the hydrophobization treatment of cellulose fibres using alkyl ketene dimers and alkenyl succinic acid anhydrides. Colloids Surf A 2007; 297: 203-10.

[28] Wang L, Dong W, Xu Y. Synthesis and characterization of hydroxypropyl methylcellulose and ethyl acrylate graft copolymers Carbohydr Polym 2007; 68: 626-36.

[29] Inagaki M, Kobayashi S, Kojin F, Tanaka N, Morishita T, Tryba B. Pore structure of carbons coated on ceramic particles. Carbon 2004; 42: 3153-8.

[30] Ibrahim M. Development of a spectroscopic technique for the study of water hyacinth as indicator for pollutants. Thesis, Physics Department, Faculty of Science, Cairo University 1996.

[31] Ahmed MA, El Bahy GS, Ibrahim M. Spectroscopic and electrical study of water hyacinth root. Bull NRC Egypt 2004; 29: 523-33.

[32] Ibrahim M, Koglin E. Vibrational spectroscopic study of some alkali metal acetates. Acta Chim Slov 2004; 51: 453-9.

[33] Ibrahim M, Nada A, Kamal D-E. DFT and FTIR spectroscopic study of carboxyl group. Indian J Pure Appl Phys 2005; 43: 911-7.

[34] Ibrahim M, Scheytt T. Increasing the ability of water hyacinth for removing cadmium: Proceedings of the $2^{\text {nd }}$ International Congress on Environmental Planning and Management. TU Berlin, Berlin, Germany 2007; 231-4.

[35] Frisch M J, Truck G W, Schlegel H B, et al. GAUSSIAN03 Revision B05. Gaussian Inc.; 2003.

[36] Ibrahim M, Abd-El-Aal M. Spectroscopic study of heavy metals interaction with organic acid. Int J Environ Pollut 2008; 35: 99110 .

[37] Ibrahim M, Jameel Hameed A, Jalbout A. Molecular spectroscopic study of river Nile sediment in the greater Cairo region. Appl Spectr 2008; 62: 306-11.

[38] Adebajo M O, Frost R L. Acetylation of raw cotton for oil spill cleanup application: an FTIR and C-13 MAS NMR spectroscopic investigation. Spectrochim Acta Part A 2004; 60: 2315-3221.

[39] Sun X-F, Sun R, Sun J-X. Acetylation of rice straw with or without catalysts and its characterization as a natural sorbent in oil spill cleanup. J Agric Food Chem 2002; 50: 6428-33.

[40] Ibrahim M, Osman O. Spectroscopic analysis of cellulose: FTIR and molecular modelling study. J Comput Theor Nanosci 2009; accepted [Epub ahead of print]. 